\title{
Climate and forests: The tradeoff between forests as a source for producing bioenergy and as a carbon sink.*
}

\author{
Michael Hoel $^{\dagger} \quad$ Thea Marcelia Sletten
}

September 17, 2015

\begin{abstract}
Forest harvests are a possible source of second-generation wood-based bioenergy. The carbon stored in the forest is highest when there is little or no harvest from the forest. Increasing the harvest from a forest, in order to produce more bioenergy, may thus conflict with the direct benefit of the forest as a carbon sink. We analyze this conflict using a simple model where bioenergy and fossil energy are perfect substitutes. Our analysis shows how the social optimum will depend on the size of the climate cost, and how the social optimum may be obtained by suitable taxes and subsidies.
\end{abstract}

Keywords: climate, carbon, bioenergy, forests.

JEL classification: Q30, Q42, Q54, Q58.

${ }^{*}$ This article is based on Sletten's master thesis (Sletten (2012)). While carrying out this research the authors have been associated with CREE -Oslo Centre for Research on Environmentally friendly Energy. CREE is supported by the Research Council of Norway.

† Corresponding author, Department of Economics, University of Oslo, P.O. Box 1095, Blindern, NO-0317 Oslo, Norway; e-mail: mihoel@econ.uio.no

¥Senior adviser at the Norwegian Environment Agency. The content of this article does not reflect the official opinion of the Norwegian Environment Agency. Responsibility for the information and views expressed in the article lies entirely with the authors 


\section{Introduction}

An increasing concern for climate change has made many countries consider biofuel and other forms of bioenergy as an important alternative to fossil energy. However, concerns have been raised about the use of bioenergy, at least of firstgeneration food-crop-based biofuels. The critique has partly been due to the upward pressure such biofuel production has put on food prices (Chakravorty et al. (2008), Bahel et al. (2013) and Hassler and Sinn (2012)). This type of biofuel has also been criticized for the greenhouse gas emissions related to growing and processing. Obvious sources of emissions from biofuel production include the use of fertilizer when growing energy crops (Crutzen et al. (2008)), as well as the use of fossil energy in the harvesting and processing of the crops (Macedo et al. (2008)). A second problem with the production of bioenergy is that it may cause carbon emissions due to direct and indirect land use changes (see e.g. Searchinger et al. (2008), Berndes et al. (2010), Andrade de Sá et al. (2013)). This is true both for conversion of grazing land and forest land to land for producing crops for bioenergy. For both types of land the land conversion may give a loss of carbon stored in the soil, and for forest land there may in addition be a loss of forest carbon stocks.

An alternative to converting grazing land or forest land into land for growing suitable crops for bioenergy production is to use the harvests from standing forests to produce bioenergy. However, wood-based bioenergy from standing forests is not unproblematic from a climatic point of view. The carbon stored in the forest is highest when there is little or no harvest from the forest. Hence, increasing the harvest from a forest in order to produce more bioenergy may conflict with the direct benefit of the forest as a sink of carbon.

Wood-based bioenergy may take many forms, including e.g. raw firewood, processed charcoals, and pellets. The possibility of producing liquid biofuel from cellulosic biomass may also be a promising alternative to using food crops (Hill et al. (2006)). The common denominator is that there is an underlying biological process that will remove carbon from the atmosphere and store it in biological materials. To analyze the climatic effects of wood-based bioenergy from standing forests in more detail, we present a simple but general model of this biological 
process and the interactions between the gradual forest growth inducing depletion of atmospheric carbon and the instantaneous emission from energy consumption.

We present our model in section 2. In this model bioenergy and fossil energy are assumed perfect substitutes. The cost of producing fossil energy is assumed increasing in cumulative extraction, so that in the long run fossil energy production will tend to zero. In section 3 we derive the properties of the social optimum, and show that there will exist a phase prior to the non-fossil era when bioenergy and fossil energy will both be produced. Our analysis shows how the social optimum will depend on the social cost of carbon; henceforth called the climate cost. In particular, we show that the long-run carbon stock contained in the forest is higher the higher is the climate cost. The long-run output level of bioenergy may be either increasing or declining in the size of the climate cost, depending both on the size of this cost and on the cost of producing bioenergy.

In section 4 we briefly describe the unregulated market economy, and show how the equilibrium in such an economy differs from the social optimum. In section 5 we show that the equilibrium of the market economy will coincide with the social optimum if all carbon emissions to the atmosphere are taxed at a rate equal to the size of the climate cost, and carbon sequestration through forest growth is subsidized at the same rate. If policy is restricted to taxes on the two types of energy, the first-best may nevertheless be achieved in our simple model. The tax rate on fossil energy should in this case be equal to the size of the climate cost, while the tax rate on bioenergy will generally differ from the fossil energy tax rate. If there is a binding political constraint on how high the tax on fossil energy can be, this constraint may affect the (second-best) optimal tax on bioenergy. In many recent papers exploring the interactions between renewable and non-renewable energy sources (Hoel (2010), Grafton et al. (2012), Gronwald et al. (2013)), the focus is primarily on how policy measures may affect the extraction path of the non-renewable energy source. In this paper the focus is instead on the optimal supply of bioenergy, and how to achieve this with policy measures. 


\section{The model}

There are two types of energy: energy produced using fossil materials and energy produced with biological material from forests, denoted fossil energy and bioenergy, respectively. The two energy types are perfect substitutes, but differ in production costs and environmental impact. Fossil energy, $R_{t}$, is produced from a non-renewable stock, $S_{t} \geq 0$, such that the change in the resource stock is given by the gross production,

$$
\dot{S}_{t}=-R_{t}
$$

As the fossil energy source gets depleted it is necessary to utilize less accessible sources, like deep water oil drilling, or use unconventional techniques, like fracking. In a similar manner as Grafton et al. (2012) we let the technology constraint be captured in the stock dependent unit cost of extraction, increasing as the stock gets depleted: $c=c\left(S_{t}\right): c^{\prime}\left(S_{t}\right)<0, c^{\prime \prime}\left(S_{t}\right)>0$ and $c\left(S_{t}\right) \rightarrow \infty$ as $S_{t} \rightarrow 0$. The increasing extraction cost will be the binding constraint, and will reduce the extraction rate to zero before the resource is completely exhausted.

Bioenergy production is modeled as harvest of available vegetation, which in our case is assumed to be boreal forests or other relatively slow growing forests. We will use a logistic growth model (Perman et al. (2003)), which gives a suitable description of the growth of these types of crops. The volume of the forest at time $t$ is denoted $V_{t}$, and forest growth is given by the function $f\left(V_{t}\right)$. This function satisfies $f^{\prime}\left(V_{t}\right)>0$ whenever $V<V_{M S Y}$, where $V_{M S Y}$ is the maximum sustainable yield, i.e. $f^{\prime}\left(V_{M S Y}\right)=0$ and $f\left(V_{M S Y}\right)=\max (f(V))$. For $V>V_{M S Y}$ we assume $f^{\prime}\left(V_{t}\right)<0$. In both cases $f^{\prime \prime}\left(V_{t}\right)<0$ for all $V_{t}$. In addition $f(0)=f\left(V_{\max }\right)=0$, which means that without harvest the forest volume will stabilize at the level $V_{\max }$, corresponding to the maximum volume. One advantage with this type of function is that it creates a capacity constraint on the bioenergy production, where $V_{M S Y}$ is the maximal possible production. Like Gronwald et al. (2013) we find this to be a more realistic case than the using a typical non-constrained backstop technology. However, the main advantage of using a general logistic growth model, is the ability to capture the dynamics of the depletion of atmospheric carbon through crop growth. A simple sketch of a possible growth function shown in Figure 1.

This simple representation of forest growth ignores the fact that forest growth 


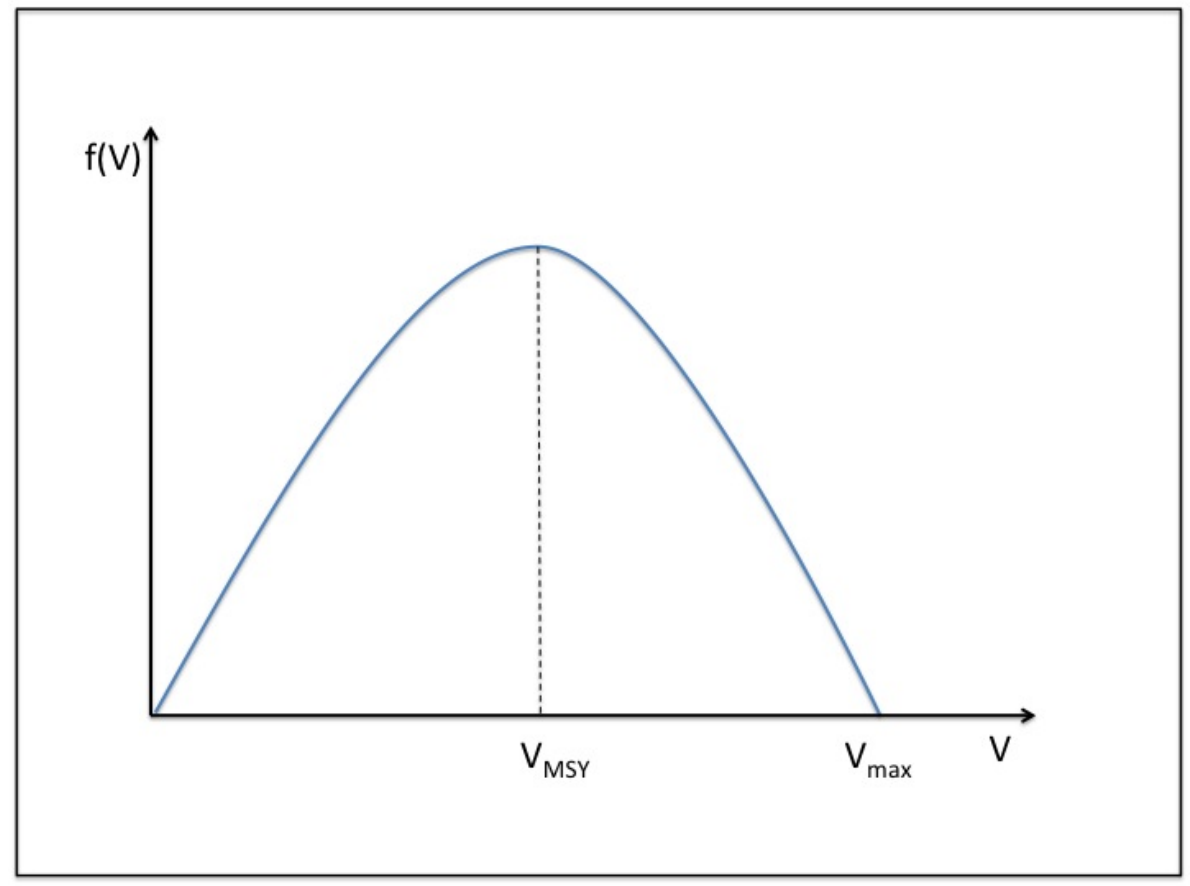

Figure 1: Example of a general logistic growth model

may be faster the higher the content of $\mathrm{CO}_{2}$ in the atmosphere, see e.g. Huang et al. (2007) . A brief discussion of this issue is given in the end of this section.

The change in the volume of the forests at time $t$ is equal to the forest growth minus the harvest $H_{t}$ :

$$
\dot{V}_{t}=f\left(V_{t}\right)-H_{t},
$$

The cost of harvesting is given by the cost function $b=b\left(H_{t}\right): b^{\prime}\left(H_{t}\right)>$ $0, b^{\prime \prime}\left(H_{t}\right) \geq 0$.

We disregard the (usually small) time lag between extraction/harvest and the production of energy, and denote total energy production and consumption by $E_{t}=R_{t}+H_{t}$. This total energy production will equal the total gross emissions from energy consumption with appropriate adjustment of the units. The net amount of carbon released into the atmosphere equals these emissions minus the carbon that is removed from the atmosphere due to the forest growth, $f\left(V_{t}\right)$. Hence, at time $\mathrm{t}, E_{t}-f\left(V_{t}\right)$ is released to the atmosphere.

We follow the recommendations by David Archer (2005) when modeling at- 
mospheric carbon and its decay. He states that "A better approximation of the lifetime of fossil fuel CO2 for public discussion might be "300 years, plus 25\% that lasts forever." (Archer (2005)). We will capture this by dividing the atmospheric carbon into two repositories, $A^{1}$ and $A^{2}$, as done by Farzin and Tahvonen (1996). $75 \%$ of the emissions will go into $A_{1}$, which has a corresponding depletion rate $\alpha$. The other $25 \%$ will end up in reservoir $A_{2}$, which has no intrinsic depletion rate. With total emissions given by $E_{t}$, the atmospheric carbon changes according to the equations below.

$$
\begin{aligned}
A_{t} & =A_{t}^{1}+A_{t}^{2} \quad \text { where } \\
\dot{A_{t}^{1}} & =\frac{3}{4}\left(E_{t}-f\left(V_{t}\right)\right)-\alpha A_{t}^{1} \\
\dot{A_{t}^{2}} & =\frac{1}{4}\left(E_{t}-f\left(V_{t}\right)\right) .
\end{aligned}
$$

The social benefit of energy consumption is given by the utility function $B=$ $B\left(E_{t}\right)$. We can interpret $B(E)$ as a reduced form function giving utility as a function of fossil energy plus bioenergy when other energy (nuclear and renewable) are optimally chosen, assuming these are either imperfect substitutes to $E$ or have increasing marginal costs of production. The utility function $B\left(E_{t}\right)$ satisfies the conditions $B^{\prime}\left(E_{t}\right)>0$ and $B^{\prime \prime}\left(E_{t}\right)<0$. The environmental damage from atmospheric carbon is assumed to be strictly increasing: $D=D\left(A_{t}\right): D^{\prime}\left(A_{t}\right)>0$ and $D^{\prime \prime}\left(A_{t}\right) \geq 0$.

\section{The social optimum}

The net social welfare at time $t$ is given by the benefits from energy consumption, subtracted production costs and the damage of atmospheric carbon,

$$
U_{t}=B\left(E_{t}\right)-c\left(S_{t}\right) R_{t}-b\left(H_{t}\right)-D\left(A_{t}\right) .
$$


The social optimum is found by maximizing the discounted social welfare across all time periods:

$$
\begin{aligned}
& \max _{\left\{R_{t}\right\},\left\{H_{t}\right\}} \int_{0}^{\infty} U_{t} e^{-\rho t} d t \\
& \text { subject to (1)- (5). }
\end{aligned}
$$

where $\rho$ is the discount rate.

Using standard optimal control theory, we construct the current value Hamiltonian and derive the corresponding necessary conditions for an interior optimum:

$$
\begin{aligned}
& \mathcal{H}_{t}= B\left(E_{t}\right)-c\left(S_{t}\right) R_{t}-b\left(H_{t}\right)-D\left(A_{t}\right)+\kappa_{t}\left[-R_{t}\right]+ \\
& \eta_{t}\left[f\left(V_{t}\right)-H_{t}\right]+v_{t}^{1}\left[\frac{3}{4}\left(R_{t}+H_{t}-f\left(V_{t}\right)\right)-\alpha A_{t}^{1}\right] \\
& v_{t}^{2}\left[\frac{1}{4}\left(R_{t}+H_{t}-f\left(V_{t}\right)\right)\right] \\
& \frac{\partial \mathcal{H}}{\partial R_{t}}=B^{\prime}\left(E_{t}\right)-c\left(S_{t}\right)-\kappa_{t}+v_{t}^{1} \frac{3}{4}+v_{t}^{2} \frac{1}{4}=0 \\
& \frac{\partial \mathcal{H}}{\partial H_{t}}=B^{\prime}\left(E_{t}\right)-b^{\prime}\left(H_{t}\right)-\eta_{t}+v_{t}^{1} \frac{3}{4}+v_{t}^{2} \frac{1}{4}=0
\end{aligned}
$$

The $v_{t}^{j}$-values will always be negative as they represent the value of adding more carbon into the atmosphere. The negative, weighted sum of the two $v_{t}^{j}$ terms will represent the climate cost (often called the social cost of carbon). We will denote this climate cost $\tau_{t}=-\left(\frac{3}{4} v_{t}^{1}+\frac{1}{4} v_{t}^{2}\right)$, giving a more compact version of the first order conditions,

$$
\begin{aligned}
& B^{\prime}\left(E_{t}\right)=c\left(S_{t}\right)+\kappa_{t}+\tau_{t} \\
& B^{\prime}\left(E_{t}\right)=b^{\prime}\left(H_{t}\right)+\eta_{t}+\tau_{t}
\end{aligned}
$$

The first order conditions have a well-known economic interpretation: The marginal benefit of increasing energy consumption must equal the marginal cost of increasing production of any of the two energy types. The cost of fossil energy depends on the real unit cost, $c\left(S_{t}\right)$, the resource rent, $\kappa_{t}$, and the climate cost $\tau_{t}$. The social 
cost of producing bioenergy depends on the real marginal cost, $b^{\prime}\left(H_{t}\right)$, the shadow price of the standing forests, $\eta_{t}$, in addition to the climate cost $\tau_{t}$. Since the two energy types are perfect substitutes, their marginal benefits are equal. To ensure efficiency, the volume consumed of each energy type must also be such that the marginal costs are equal, described by $c\left(S_{t}\right)+\kappa_{t}=b^{\prime}\left(H_{t}\right)+\eta_{t}$.

The time development of the system is governed by the equations of motion, that is, the time development of the shadow prices:

$$
\begin{aligned}
& \dot{\kappa}_{t}-\rho \kappa_{t}=c^{\prime}\left(S_{t}\right) R_{t} \\
& \dot{\eta}_{t}-\left(\rho-f^{\prime}\left(V_{t}\right)\right) \eta_{t}=-\tau_{t} f^{\prime}\left(V_{t}\right) \\
& \dot{v_{t}^{1}}-(\rho+\alpha) v_{t}^{1}=D^{\prime}\left(A_{t}\right) \\
& \dot{v_{t}^{2}}-\rho v_{t}^{2}=D^{\prime}\left(A_{t}\right) .
\end{aligned}
$$

The corresponding transversality conditions are necessary to ensure an internal solution of the system,

$$
\begin{aligned}
& \lim _{t \rightarrow \infty} e^{-\rho t} \kappa_{t}=0 \\
& \lim _{t \rightarrow \infty} e^{-\rho t} \eta_{t}=0 \\
& \lim _{t \rightarrow \infty} e^{-\rho t} v_{t}^{j}=0 .
\end{aligned}
$$

Combining the equations above yields

$$
\begin{aligned}
\tau_{t}=-\left(\frac{3}{4} v_{t}^{1}+\frac{1}{4} v_{t}^{2}\right) & =\int_{0}^{\infty}\left(1+3 e^{-\alpha z}\right) \frac{1}{4} e^{-\rho z} D^{\prime}\left(A_{t+z}\right) d z \\
\kappa_{t} & =-\int_{0}^{\infty} e^{-\rho z} c^{\prime}\left(S_{t+z}\right) R_{t+z} d z .
\end{aligned}
$$

The climate cost (16) depends only on the marginal damage of carbon emissions, which is positive by assumption. This leads to the conclusion that all carbon emitted into the atmosphere gives the same environmental costs, regardless of whether the carbon source is fossil energy or bioenergy. The climate cost reflects the damage today, as well as all future damages, of adding one more unit of carbon into the atmosphere. If one unit is emitted at time $t$, the immediate damage is given by $D^{\prime}\left(A_{t}\right)$. If no more carbon is emitted in the future, the part stored in 
repository 2 will give a future discounted damage of $\frac{1}{4} e^{-\rho z} D^{\prime}\left(A_{t+z}\right)$, for all future times $t+z$. In repository 1 , there is also a depletion rate, so the future damage will be $\frac{3}{4} e^{-(\rho+\alpha) z} D^{\prime}\left(A_{t+z}\right)$. Summing up the combined damage over all times $t+z \geq t$ yields the expression in equation (16).

The resource rent $\kappa_{t}$ is a reflection of the added cost of producing fossil energy, due to the scarcity of the resource. The immediate effect of extracting one unit of fossil energy today is that the stock of fossil energy decreases. This will lead to an increase in the unit cost of production and thus make all future extractions more costly. The total effect of one unit extraction today is more complex, as it depends on the entire extraction future path. The main effect is still that the efficient marginal cost of extraction becomes higher than the real unit extraction cost, when scarcity is taken into account.

It is not possible to obtain an analytical expression for $\eta_{t}$, as the effective discount rate $\rho-f^{\prime}\left(V_{t}\right)$ is not constant. But by studying (13) closer, it is still possible to give this shadow price a meaningful interpretation. Keeping in mind that $\eta_{t}$ is the value of adding one more unit of standing forests, i.e. increasing $V_{t}$, one can divide $\dot{\eta}_{t}$ into three terms to easier be able to identify the different effects in play. The first term, $\rho \eta_{t}$, represents the necessary adjustment in $\eta_{t}$ to account for discounting. The second term, $-f^{\prime}\left(V_{t}\right) \eta_{t}$, takes into account that when the growth rate changes due to present volume changes, this will influence the volume in the subsequent periods. The last term, $-\tau_{t} f^{\prime}\left(V_{t}\right)$, includes the environmental impact, which arises due to changes in the efficient depletion rate.

\subsection{Steady-state solution}

In order to simplify the dynamics of the solution, we make the assumption that $D^{\prime \prime}=0$, so that $D^{\prime}$ is independent of $A .{ }^{1}$ In other words, the damage of adding one more unit of atmospheric carbon is independent of the current level of carbon in the atmosphere. It immediately follows from (16) that the climate cost takes the form

$$
\tau=\left[\frac{3}{4} \frac{1}{\rho+\alpha}+\frac{1}{4} \frac{1}{\rho}\right] D^{\prime}
$$

\footnotetext{
${ }^{1}$ This assumption is only important for the dynamics towards the steady state; in the steady state $D^{\prime}$ is constant even if $D^{\prime \prime}>0$.
} 
and is constant for all times $t$. The climate cost depends on the social discount rate $\rho$, the depletion rate $\alpha$, and the damage of atmospheric carbon, $D^{\prime}$. The first part $\frac{D^{\prime}}{\rho+\alpha}$ accounts for the damage of adding one more unit of carbon into repository 1 , while $\frac{D^{\prime}}{\rho}$ embodies the cost of adding carbon to repository 2. The weighted sum of these costs reflects the fact that when you increase emissions by one unit, $75 \%$ ends up in repository 1 and $25 \%$ ends up in repository 2, yielding a total cost of $\tau$.

The steady-state solution is characterised by $\dot{S}_{t}=\dot{V}_{t}=\dot{A}_{t}^{1}=\dot{A}_{t}^{2}=\dot{\kappa}_{t}=\dot{\eta}_{t}=0$. This removes all time-dependence, and we get the long-run or steady-state values of the variables. The equation set describing the steady-state is given by: ${ }^{2}$

$$
\begin{aligned}
R_{*} & =0 \\
A_{*}^{1} & =0 \\
A_{*}^{2} & =A_{0}^{2}+\frac{1}{4}\left[\left(S_{0}-S_{*}\right)+\left(V_{0}-V_{*}\right)\right] \\
A_{*} & =A_{*}^{2} \\
H_{*} & =f\left(V_{*}\right) \\
B^{\prime}\left(R_{*}+H_{*}\right) & =c\left(S_{*}\right)+\kappa_{*}+\tau \\
B^{\prime}\left(R_{*}+H_{*}\right) & =b^{\prime}\left(H_{*}\right)+\eta_{*}+\tau \\
\rho \kappa_{*} & =-c^{\prime}\left(S_{*}\right) R_{*} \\
\left(\rho-f^{\prime}\left(V_{*}\right)\right) \eta_{*} & =f^{\prime}\left(V_{*}\right) \tau
\end{aligned}
$$

where "*" indicates a steady-state value and initial values are marked with " 0 ".

The 9 equations (19)-(27) give the steady-state solutions for the 9 endogenous variables $S_{*}, R_{*}, V_{*}, H_{*}, A_{*}^{1}, A_{*}^{2}, A_{*}, \kappa_{*}$ and $\eta_{*}$. These equations follow immediately from our dynamic equations, with the exception of (21), which is derived as

\footnotetext{
${ }^{2}$ The steady state described by (19)-(27) will only be reached asymptotically. To see this assume that the steady state is reached at some finite date $T$. The dynamics of the system imply that all variables remain constant from $T$ and onwards. Moreover, the same dynamics imply that all variables remain constant also when we move backwards in time from $T$. But this can only be a solution to our equations if $S_{0}=S_{*}$ and $V_{0}=V_{*}$, i.e. if we already are at the steady state initially.
} 
follows:

$$
\begin{aligned}
A_{*}^{2} & =A_{0}^{2}+\int_{0}^{\infty} \dot{A}_{t}^{2} d t \\
& =A_{0}^{2}+\frac{1}{4} \int_{0}^{\infty}\left[E_{t}-f\left(V_{t}\right)\right] d t \\
& =A_{0}^{2}+\frac{1}{4} \int_{0}^{\infty}\left[R_{t}+H_{t}-\left(\dot{V}_{t}+H_{t}\right)\right] d t \\
& =A_{0}^{2}-\frac{1}{4} \int_{0}^{\infty}\left(\dot{S}_{t}+\dot{V}_{t}\right) d t \\
& =A_{0}^{2}+\frac{1}{4}\left[\left(S_{0}-S_{*}\right)+\left(V_{0}-V_{*}\right)\right]
\end{aligned}
$$

The interpretation of (21) is that in addition to the initial carbon in repository $2,1 / 4$ of the net emissions remain in the atmosphere for ever. Total emissions from $t=0$ to infinity are $S_{0}-S_{*}$ from fossil energy extraction and $V_{0}-V_{*}$ from the change in carbon contained in the biomass. If $V_{0}-V_{*}$ is less than zero, the net "emissions" from the forests will be negative. This implies that the harvest has been lower than the natural growth, which means that the production (or lack of production) of bioenergy in itself has reduced the amount of atmospheric carbon.

The production of fossil energy will necessarily tend to zero in the long run caused by the continued increase in production costs, as the resource gradually gets depleted. The resource rent will then decrease to zero (as seen from (26)), as the remaining stock of the fossil resource no longer has any value. Hence, the total energy production in the long run will solely be given by the bioenergy production, when the production of fossil energy ceases. Equation (23) shows that the steady-state production of bioenergy will equal the long-term natural growth of the forests. This means that for any positive volume $V_{*}$ (less than $V_{\max }$ ), it is possible to have positive energy production in the long run.

Even though the production of fossil energy will tend asymptotically towards zero, this is not the case for the stock of fossil energy, $S$. Since the extraction costs tend to infinity as the stock gets depleted $(c(S) \rightarrow \infty$ as $S \rightarrow 0)$, the steady state level $S_{*}$ must be strictly positive, even without taking the environmental damage into account. The steady state level of the stock will also be linked to the steadystate bioenergy production, and thus the volume of standing forests. By combining 
(23) - (25) we see that the remaining stock of the fossil energy source will be given by $c\left(S_{*}\right)=b^{\prime}\left(H_{*}\right)+\eta_{*}=b^{\prime}\left(f\left(V_{*}\right)\right)+\eta_{*}$. That is, the marginal cost of producing the last unit of fossil energy will equal the marginal cost of the steady state production of bioenergy plus the shadow price of the standing forests.

There are several different possibilities for the steady state solutions for $\eta_{*}$ and $V_{*}$, depending on the underlying assumptions and the specific functions involved. This will be discussed in the next subsections.

\subsection{The dynamics toward the steady state}

This section gives a more detailed picture of the properties of the steady state and the dynamics toward the steady state. To be able to discuss the dynamic properties, we have made some simplifications. When the system has reached the steady state, fossil energy production will be zero, so only the bioenergy production will affect the marginal benefit $B^{\prime}$. However, when discussing the saddle path, this will generally not be the case. To be able to clearly display the interactions between the shadow price and the forest volume, we will disregard the interaction with fossil energy in the discussions below. The arguments will still be valid for any constant level of fossil energy production. (In the end of section 3.3 we briefly return to the consequences of a declining output of fossil energy.)

To construct a phase diagrams we need to find the conditions ensuring $\dot{\eta}=0$ and $\dot{V}=0$. Consider first the condition giving $\dot{\eta}=0$. From the steady-state equation (27) we have

$$
\dot{\eta}=0 \rightarrow \quad \eta=\frac{\tau f^{\prime}(V)}{\rho-f^{\prime}(V)} \text { for } f^{\prime}(V) \neq \rho
$$

As seen from this equation, $\eta$ is not defined for $\rho=f^{\prime}(V)$, and we will denote this limit volume $V^{\rho}$. In the appendix we show that the curve giving $\dot{\eta}=0$ is discontinuous in $V=V^{\rho}$, as the curve tends to $+\infty$ when $V$ approaches $V^{\rho}$ from above and $-\infty$ when $V$ approaches $V^{\rho}$ from below. Moreover, for $V>V^{\rho}$ this curve is downward sloping and cuts the horizontal axis at $V_{M S Y}$. For $V<V^{\rho}$ it is shown that $\eta$ is declining to the right of the $\dot{\eta}=0$ curve, and increasing to the left. The opposite holds for $V>V^{\rho}: \eta$ is declining to the left of the $\dot{\eta}=0$ curve, 
and increasing to the right. These properties of the curve for $\dot{\eta}=0$ are used in the phase diagrams below.

Consider next the condition giving $\dot{V}=0$. Combining the steady-state equation (27) with the first-order conditions (25) we have

$$
\dot{V}=0 \rightarrow \quad \eta=B^{\prime}(f(V))-b^{\prime}(f(V))-\tau
$$

Since $B$ and $f$ are strictly concave and $b$ is convex it is clear that this curve is U-shaped with its minimum when $f^{\prime}(V)=0$, i.e. at $V_{M S Y}$. The minimum value of $\eta$ may be positive or negative depending on the size of $\tau$. In both cases it is shown in the appendix that $V$ is declining for values of $\eta$ below this curve, and increasing for for values of $\eta$ above this curve. These properties of the curve for $\dot{V}=0$ are used in the phase diagrams below.

\subsection{Low-cost bioenergy}

In this section we consider low-cost bioenergy. More precisely, we make the following assumption:

$$
B^{\prime}\left(f\left(V_{M S Y}\right)\right)-b^{\prime}\left(f\left(V_{M S Y}\right)\right)>0
$$

This means that in the absence of any fossil energy production and climate costs, short-run maximization of $U$, implying $B^{\prime}(H)-b^{\prime}(H)=0$, would given an unsustainable value of $H$ (i.e. $H>f\left(V_{M S Y}\right)$ ). Hence, in this case the biological dynamics of the forests (given by (2)) is a restriction that reduces social welfare in the absence of climate costs, since optimal fossil energy production must approach zero in the long run. As explained above, the minimum value of $\eta$ in Figure 2 and Figure 3 is given by $\eta=B^{\prime}\left(f\left(V_{M S Y}\right)\right)-b^{\prime}\left(f\left(V_{M S Y}\right)\right)-\tau$. Due to assumption (30), this minimum value of $\eta$ is positive if $\tau$ is sufficiently small (Figure 2), but may be negative if $\tau$ is sufficiently large (Figure 3 ).

We will start by looking at the case where the climate cost $\tau$ is "low", meaning that $B^{\prime}>b^{\prime}+\tau$ for all volumes $V$ (Figure 2). In this case it will be optimal to choose a steady-state volume that ensures a high production volume of bioen- 
ergy. The highest possible steady state bioenergy production is obtained when $V=V_{M S Y}$, but due to discounting, the steady-state volume will end up strictly less than $V_{M S Y}$. If $V_{0}<V_{*}$ the value of standing forests starts at a higher level than the marginal social profit $\left(\eta_{0}>B^{\prime}\left(f\left(V_{0}\right)\right)-b^{\prime}\left(f\left(V_{0}\right)\right)-\tau_{0}\right)$. It will then be optimal to harvest below the growth rate, as this will lead to an increase in both the volume and the growth rate of the forests. Along the saddle path $\eta$ is decreasing, and the volume will continue to increase until the steady state is reached (asymptotically). A similar argument can be used when $V_{0}>V_{*}$, but then we have the opposite movements in the variables. In both cases, the closer the minimum point of the $\dot{V}=0$ curve is to zero, the closer the steady-state volume gets to $V_{M S Y}$. Thus with a low climate cost $\eta_{*}$ will be positive, as the $\dot{\eta}=0$ locus is above zero between $V^{\rho}$ and $V_{M S Y}$.

A special case of a low climate cost is that $\tau=0$. This case of no climate cost is of particular interest, as the unregulated market outcome in the absence of any externality will coincide with the social optimum. The curve for $\dot{V}=0$ will be as drawn in Figure 2. When $\tau=0$ it is clear from (13) that $\dot{\eta}=0$ only if $\eta=0$ or $f^{\prime}(V)=\rho$ (i.e. $V=V^{\rho}$ ). Hence, the downward sloping curve for $\dot{\eta}=0$ in Figure 2 takes the limiting upside-down T-shaped form as illustrated in Figure 4. In this case the steady state value of $V$ is $V^{p}$.

Consider next the case for which the climate cost is so high that $B^{\prime}\left(f\left(V_{M S Y}\right)\right)-b^{\prime}\left(f\left(V_{M S Y}\right)\right)-\tau<0$. In this case the minimum value of $\eta$ is negative, as illustrated in Figure $3^{3}$. The difference from the low-cost case is that the higher climate cost makes it less profitable to produce bioenergy, and the system is then pushed towards a higher steady-state volume than in the case of a low climate cost. The steady-state volume will now be to the right of $V_{M S Y}$, and the corresponding $\eta_{*}$ will be negative. ${ }^{4}$

Although the sign of $\eta_{*}$ is ambiguous, $\eta_{*}+\tau$ will always be positive for a

\footnotetext{
${ }^{3}$ Assuming for now that there is only one equilibrium point in this case, even though it is possible to get multiple equilibria if the $\dot{V}=0$ curve cross the $\dot{\eta}=0$ curve on the left hand side of $V^{\rho}$. Multiple equilibria are discussed in more detail in section 3.5.

${ }^{4}$ We disregard cases where $\tau$ is so large that the $\dot{\eta}=0$ and $\dot{V}=0$ do not intersect for an interior value of $V$.
} 


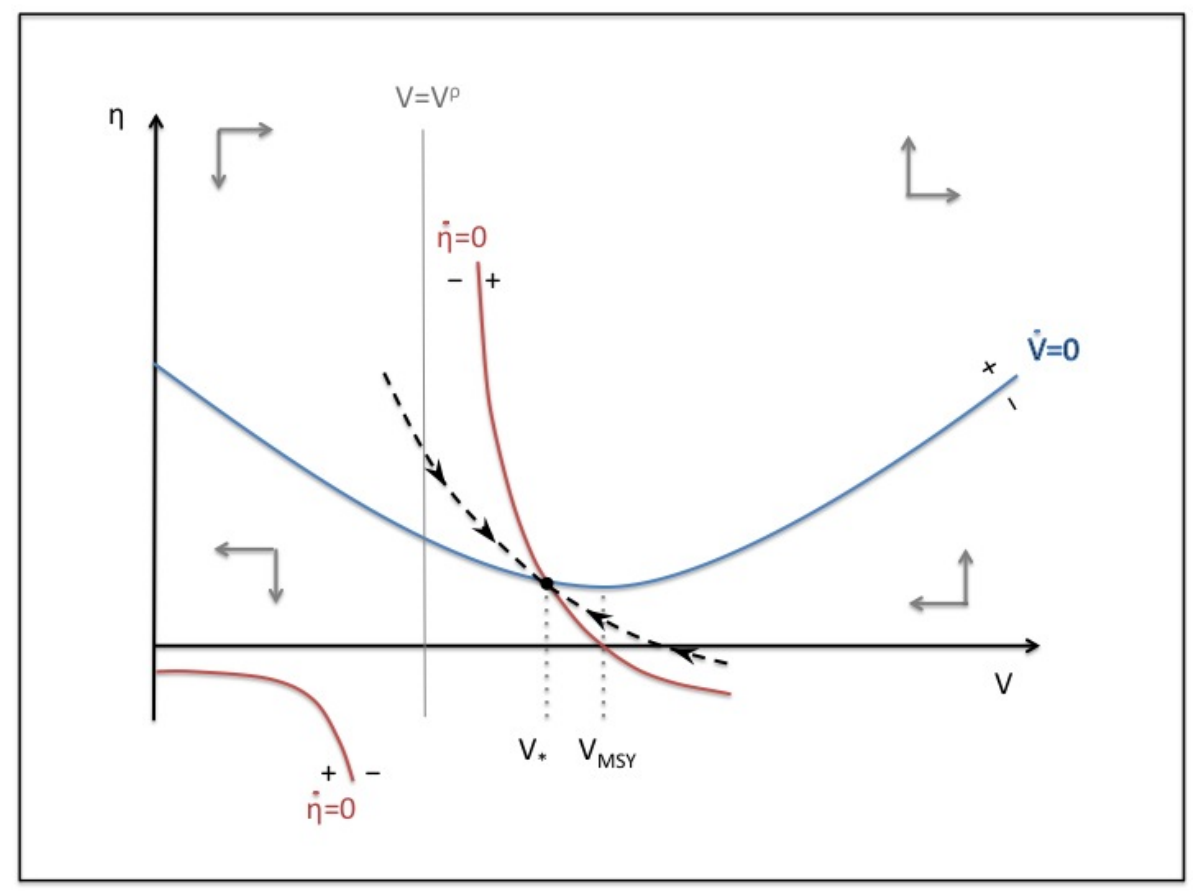

Figure 2: Phase diagram for low cost bioenergy with a low climate cost.

positive climate cost. This follows from (27):

$$
\eta_{*}+\tau=\frac{\tau f^{\prime}\left(V_{*}\right)}{\rho-f^{\prime}\left(V_{*}\right)}+\tau=\frac{\rho}{\rho-f^{\prime}\left(V_{*}\right)} \tau
$$

which is positive for all equilibria with $\tau>0$, since $f^{\prime}\left(V_{*}\right)<\rho$ for $\tau>0$.

The formal analysis above was done assuming $R=0$, which is unproblematic with regards to the $\dot{\eta}=0$ loci, as equation (28) is independent of the value of $R$. However, the position of the curve for $\dot{V}=0$, given by $\eta=B^{\prime}(f(V)+R)-$ $b^{\prime}(f(V))-\tau$, is lower the higher is $R$, since $B^{\prime \prime}<0$. As $R$ gradually declines as we approach the steady state, this means that this curve is gradually moving upwards. This will make the detailed dynamics of $V$ and $\eta$ slightly different than what we have illustrated in Figure 2-4. In particular, the approach of $\eta$ towards its steady state value may no longer be monotonic. This may in turn have implications for the detailed time path of the bioenergy production towards its steady-state value $f\left(V_{*}\right)$. 


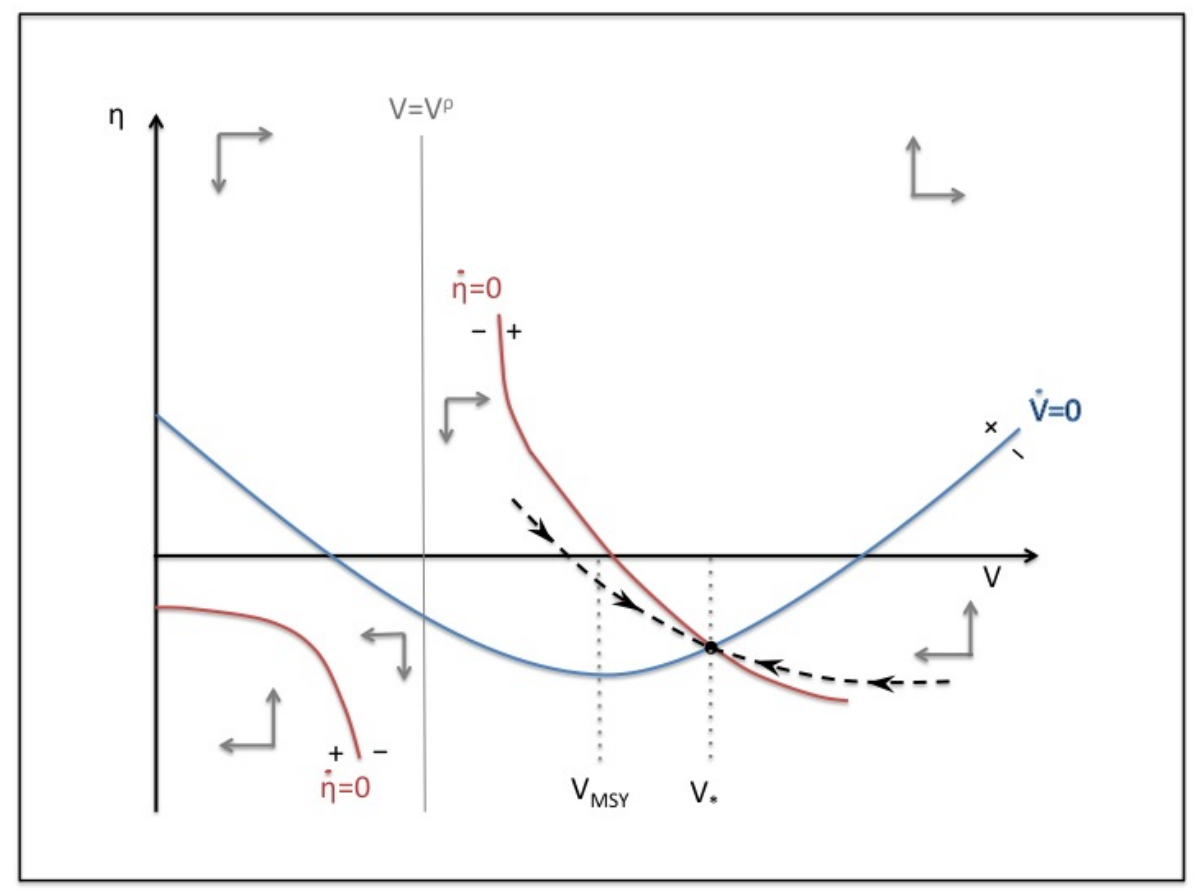

Figure 3: Phase diagram for low cost bioenergy with a medium to high climate cost.

\subsection{High-cost bioenergy}

Assume now that (30) doesn't hold, that is, $B^{\prime}\left(f\left(V_{M S Y}\right)\right)-b^{\prime}\left(f\left(V_{M S Y}\right)\right) \leq 0$. This means that in the absence of any fossil energy production and climate costs, shortrun maximization of $U$, implying $B^{\prime}(H)-b^{\prime}(H)=0$, would give a sustainable value of $H$ (i.e. $H \leq f\left(V_{M S Y}\right)$ ). In this case the minimum value of $\eta$ is negative for all $\tau \geq 0$. Figure 3 is an example of this case for a $\tau>0$.

If cost of bioenergy production is sufficiently high, we could have $B^{\prime}(0)-$ $b^{\prime}(0) \leq 0$, in which case the U-shaped curve for $\dot{V}=0$ is below the horizontal axis for all $V \in\left[0, V_{\max }\right]$. It is then optimal to have no bioenergy production even if fossil energy production is zero, no matter what non-negative climate cost we have. Whenever $B^{\prime}(0)-b^{\prime}(0)>0$ and $\tau>0$ the $\mathrm{U}$-shaped curve for $\dot{V}=0$ will intersect the $\dot{\eta}=0$ locus for some $V<V_{\text {max }}$. The long-run equilibrium will then be characterized by $V_{M S Y}<V_{*}<V_{\max }$ and $\eta_{*} \leq 0$, for any strictly positive value of $\tau$. The limiting case of $\tau=0$ in discussed in section 4 . 


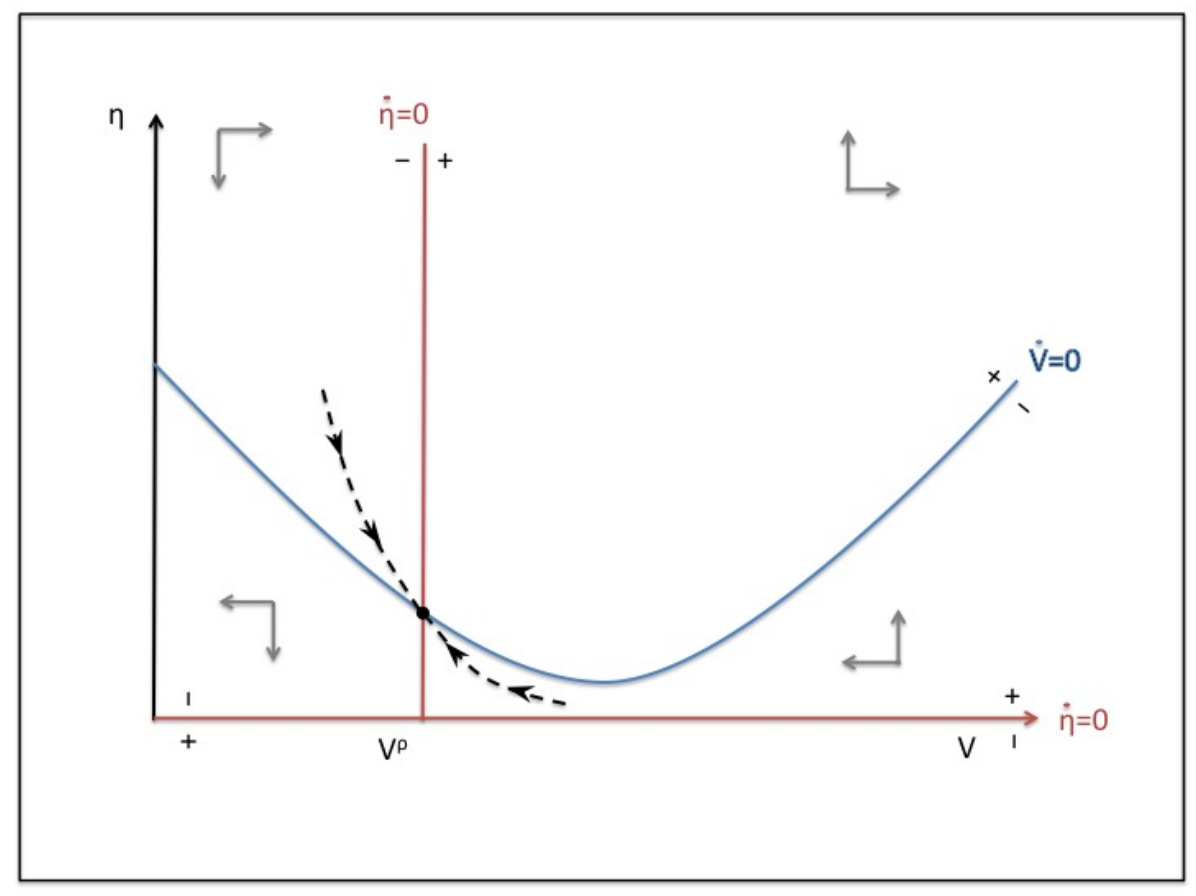

Figure 4: Phase diagram for low cost bioenergy with no climate cost.

\subsection{Multiple steady states}

In the discussion above we assumed that there was only one steady-state equilibrium. As Figure 5 reveals, however, there may be multiple steady-states. For Figure 5 to be valid, we must either have a high climate cost, or a low climate cost coupled with high-cost bioenergy. The figure clearly shows that there are two stable steady-state equilibria, $V_{\text {low }}$ and $V_{\text {high }}$, and one unstable, $V_{\text {med }}$, lying between the two stable equilibria. This means that there are two possible time paths that solve the maximization problem (7). The low steady-state volume, $V_{\text {low }}$, will be realized if $V_{0}<V_{\text {med }}$, that is, the initial volume is less than the volume corresponding to the unstable equilibrium. If $V_{0}>V_{\text {med }}$ the steady-state volume will be $V_{\text {high }}$.

When there is no climate cost, multiple equilibria can only arise if the cost of producing bioenergy is high, i.e. $B^{\prime}\left(f\left(V_{M S Y}\right)\right)-b^{\prime}\left(f\left(V_{M S Y}\right)\right) \leq 0$. This case is shown in Figure 6 . The two cases are very similar, the main difference being that in the no externality case the steady state shadow price of the standing forests will 
never be negative.

Common for all stable steady-state equilibria is that the unregulated market will always have a lower steady-state forest volume than what is socially optimal.

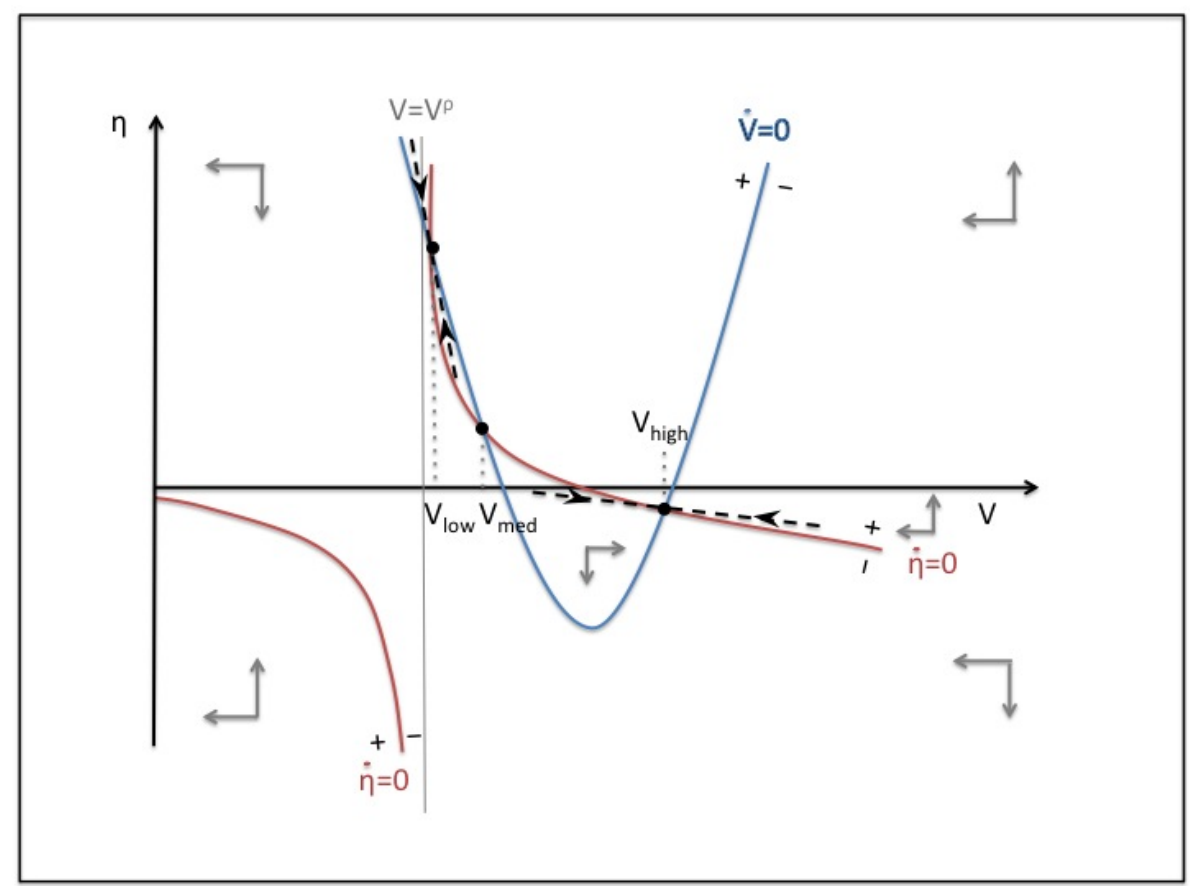

Figure 5: Phase diagram with multiple equilibria for high cost bioenergy and/or a high climate cost. 


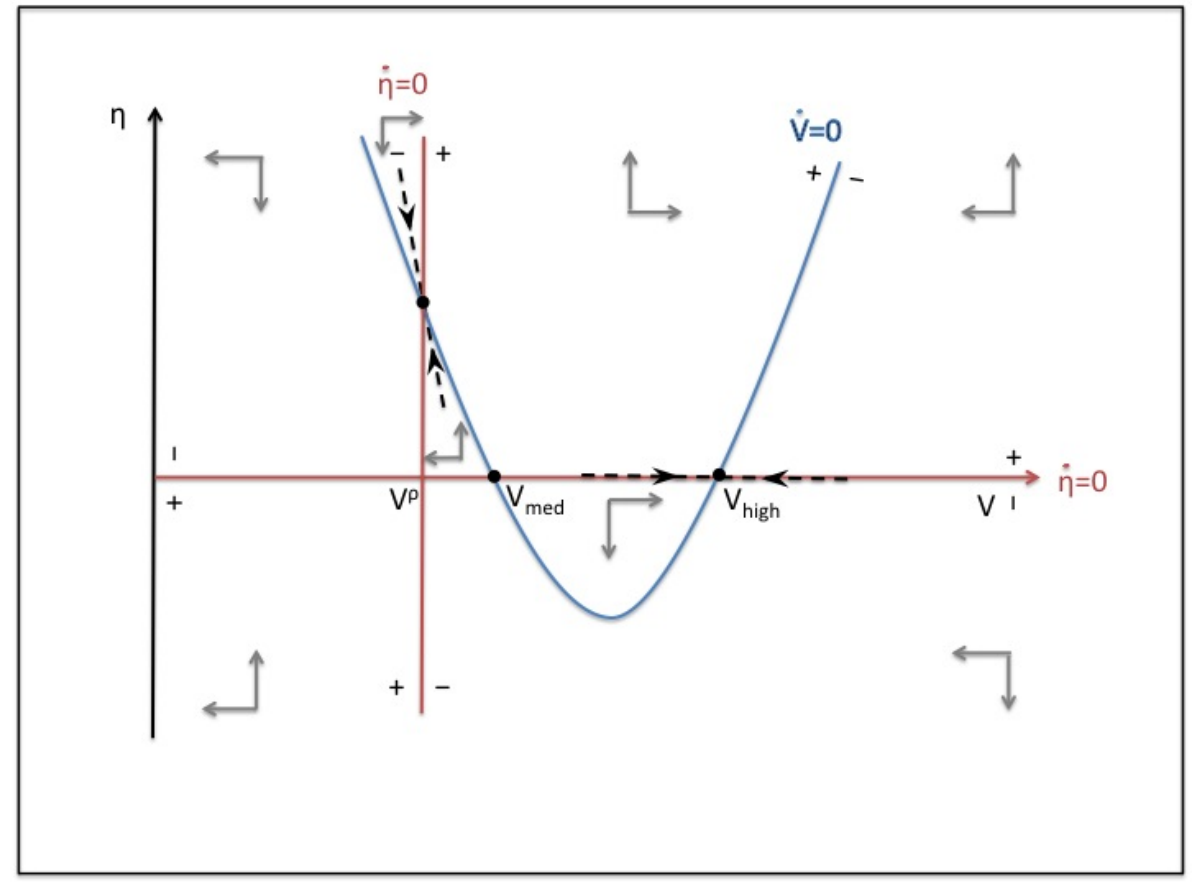

Figure 6: Phase diagram with multiple equilibria for high cost bioenergy with no climate cost.

\subsection{Effects of a higher climate cost}

To see how the steady-state values depend on the size of the climate cost, we differentiate the equations (19)-(27) with respect to $\tau$. In the appendix we derive 
the following results:

$$
\begin{aligned}
\frac{d V_{*}}{d \tau} & =\frac{\rho}{K}>0 \\
\frac{d S_{*}}{d \tau} & =\frac{1}{-c^{\prime \prime} K}\left[K-\rho B^{\prime \prime} f^{\prime}\right]>0 \\
\frac{d A_{*}}{d \tau} & =-\left(\frac{d V_{*}}{d \tau}+\frac{d S_{*}}{d \tau}\right)<0 \\
\frac{d H_{*}}{d \tau} & =f^{\prime}\left(V_{*}\right) \frac{d V_{*}>}{d \tau}<\text { depending on } V_{*}{ }^{<} V_{M S Y} \\
\frac{d \eta_{*}}{d \tau} & =\frac{1}{K}\left[\left(B^{\prime \prime}-b^{\prime \prime}\right)\left(f^{\prime}\right)^{2}+\left(\eta_{*}+\tau\right) f^{\prime \prime}\right]<0 \\
\frac{d\left(\eta_{*}+\tau\right)}{d \tau} & =\frac{\rho}{K}\left(B^{\prime \prime}-b^{\prime \prime}\right) f^{\prime}>0 \text { depending on } V_{*}>V_{M S Y} \\
K & =\left(B^{\prime \prime}-b^{\prime \prime}\right) f^{\prime}\left(\rho-f^{\prime}\right)-\left(\eta_{*}+\tau\right) f^{\prime \prime}>0
\end{aligned}
$$

Notice that $V_{*}$ is unambiguously increasing with increased $\tau$. For low-cost bioenergy, this implies that as $\tau$ increases from 0 to $B^{\prime}\left(f\left(V_{M S Y}\right)\right)-b^{\prime}\left(f\left(V_{M S Y}\right)\right)$, the steady state bioenergy production $H_{*}$ increases. However, as $\tau$ increases further, $f^{\prime}$ becomes negative, so $H_{*}$ declines with a rising $\tau$. This implies that a higher climate cost will only result in a higher steady-state level of bioenergy production if the steady-state volume is sufficiently low, that is, below $V_{M S Y}$.

Since $V_{*}>V_{M S Y}$ for high-cost bioenergy, it follows from (36) that for high-cost bioenergy a higher climate cost will unambiguously give lower long-run bioenergy production.

A higher climate cost will give a larger amount of carbon in the forest and also a larger stock of unextracted fossil fuel. Hence, the long-run stock of carbon in the atmosphere is lower the higher is the climate cost. 


\subsection{Forest growth and the atmospheric content of $\mathrm{CO}_{2}$}

As mentioned previously (in section 2), forest growth may depend positively on the content of carbon in the atmosphere (Huang et al. (2007)). To find the consequence of this on our results we can replace the growth function $f(V)$ with the more general function $F(V, A)$, with the properties of $F_{V}=\partial F / \partial V$ being as before and with $F_{A}=\partial F / \partial A>0$. In the appendix it is shown that not much is changed be redoing the analysis with the function $f(V)$ replaced by $F(V, A)$. One change of some importance is that the size of the climate cost will be reduced by this change. Instead of (18) the climate cost will now be given by

$$
\tau=k\left[\frac{3}{4} \frac{1}{\rho+\alpha}+\frac{1}{4} \frac{1}{\rho}\right] D^{\prime}
$$

where $k$ will be smaller than one if $F_{A}>0$. Moreover, $k$, and hence $\tau$, will be lower the larger is $F_{A}$. The interpretation of this is obvious: If emissions of carbon to the atmosphere immediately increase forest growth and hence absorb some of the carbon emissions, the climate damage of the carbon emissions will be reduced. However, based on the findings in van der Sleen (2015), which showed that the increase in $\mathrm{CO} 2$ has not stimulated growth of tropical trees, we assume omitting this effect will not notably change the conclusions.

\section{The unregulated market}

The market outcome maximizes consumer plus producer surplus, in the absence of externalities and regulations. This means that the market outcome is identical to what the social optimum would be without any environmental costs. The steadystate properties of this outcome were illustrated by Figure 4 for the case of lowcost bioenergy and by Figure 6 for the case of high-cost bioenergy. We have shown that for both cases the socially optimal steady-state volume of the forests is higher the higher is the climate cost. It follows that the steady-state volume of the forests in an unregulated market is lower than what is socially optimal in the presence of climate costs. For the case of high-cost bioenergy (implying $V_{*}>V_{M S Y}$ for all $\tau$ and hence $H_{*}$ lower the higher is $V_{*}$ ), this implies that the steady-state bioenergy 
production in an unregulated market is higher than what is socially optimal in the presence of climate costs. For low-cost bioenergy the reverse may be true, that is, the bioenergy production in an unregulated market may be lower than what is socially optimal.

Even if the socially optimal long-run bioenergy production may be lower than the long-run bioenergy production in an unregulated market, the relationship could be the opposite in the short run. This is illustrated in Figure 7. The time paths for the unregulated marked (correponding to zero climate cost) and social optimum (positive climate cost) are denoted by UM and SO, respectively. Since the UM-curve lies above the SO-curve in the long run, we must have $V_{*}>V_{M S Y}$, as illustrated in Figure 3. Before fossil fuels are depleted, bioenergy production is determined by (11), i.e. $B^{\prime}\left(R_{t}+H_{t}\right)-b^{\prime}\left(H_{t}\right)=\eta_{t}+\tau$. The climate cost will reduce $R_{t}$ in the short run compared with the unregulated market. From the equation above we therefore see that the direct effect of increasing $\tau$ is to reduce $H_{t}$, but that the indirect effect through reduced $R_{t}$ is to increase $H_{t}$. If this indirect effect dominates the direct effect, the socially optimal bioenergy production will be higher in the near term than in the unregulated market, as illustrated in Figure 7.

A complete analysis of the effects of increasing the climate cost $\tau$ connected to both fossil energy and bioenergy prior to the steady state, is beyond the scope of the present analysis. However, to demonstrate that the case illustrated in Figure 7 at least is possible, consider the following example: Let demand be very inelastic (i.e. $B^{\prime \prime}$ large), implying that any increase in the climate cost will only give a small increase in $V_{*}$ and a small reduction in $H_{*}$. If this increase gives a substantial reduction in $R_{t}$ at early dates $\left(R_{t}\right.$ would in fact drop to zero if the increase in the climate cost was large enough), it follows that $H_{t}$ must increase at these dates (since the change in $R_{t}+H_{t}$ must be small for all dates). This will hence give a situation as described in Figure 7. 


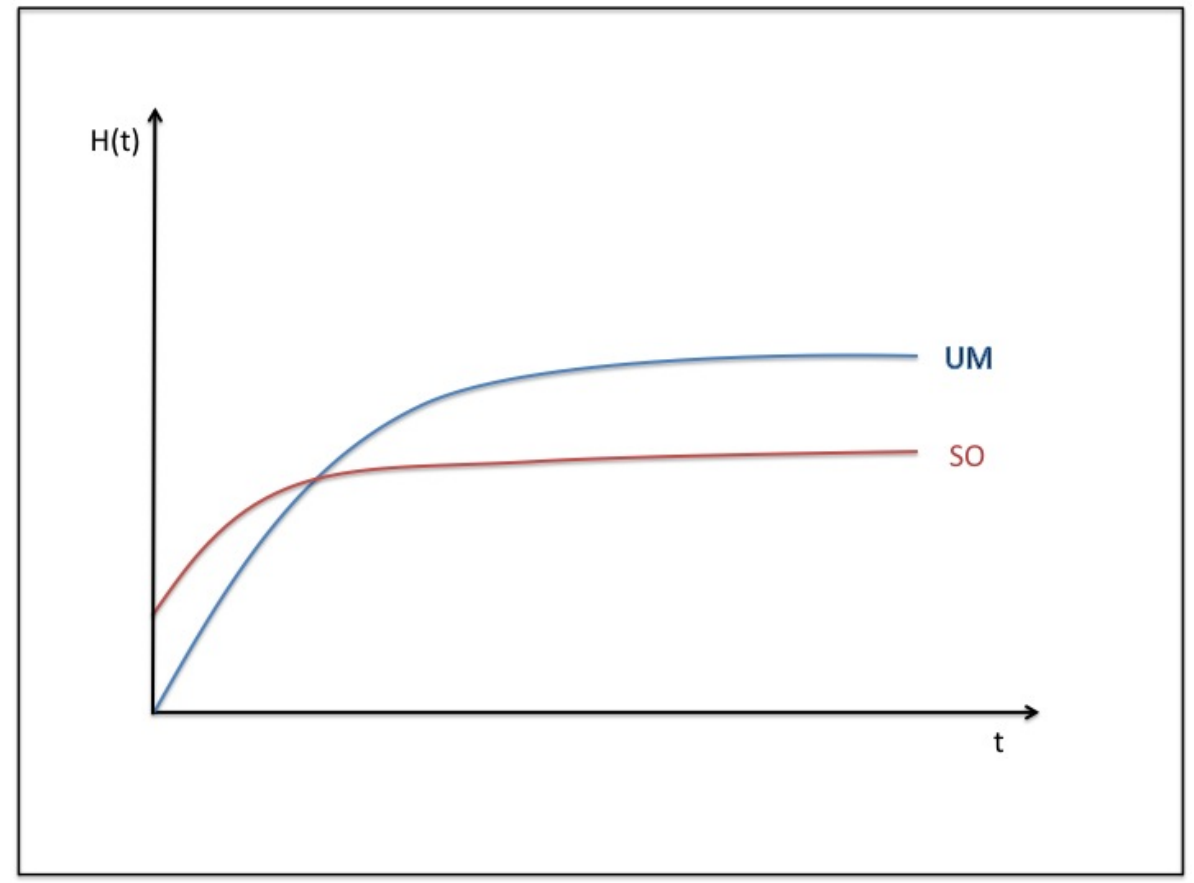

Figure 7: Sketch of possible time paths of the socially optimal bioenergy production (SO) and the production provided by the unregulated market (UM) 


\section{Policy options}

\subsection{Tax on carbon emissions}

As usual, the social optimum may be achieved by setting a Pigovian tax on net carbon emissions to the atmosphere. This tax should be equal to the climate cost given by (16), and should be applied both to the emissions from fossil energy use and to net emissions from using bioenergy (gross emissions minus growth of the forests). With such a tax scheme the market outcome will coincide with the solution to the problem described by (7), with a slightly modified "utility function" given by:

$$
U_{t}^{\text {market }}=B\left(H_{t}+R_{t}\right)-c\left(S_{t}\right) R_{t}-b\left(H_{t}\right) H_{t}-\tau_{t}\left(R_{t}-\dot{V}_{t}\right)
$$

where $\tau_{t}$ is given by (16). It is straightforward to verify that the solution to this problem is given by (10)-(13).

\subsection{Differentiated tax on energy consumption}

If the government lacks detailed and verifiable information about the forest growth at the micro level, it will not be possible to reach the first-best solution using only a tax on net carbon emission. ${ }^{5}$ Another policy option can be to impose a tax or subsidy on the different energy types. As shown below, this policy option will also reproduce the first-best solution.

The government's problem can be constructed as a Stackelberg game, where the government is the leader and announces the tax paths that it will commit to. The producers are the followers, and will maximize profits taking the announced tax plans as given. The idea behind this game is that the government can calculate how the producers will respond to the different tax paths, and based on this, choose the tax paths yielding the highest net social benefits. The government's

\footnotetext{
${ }^{5}$ Even without detailed and verifiable information about volumes and growth at the micro level (i.e. level of the individual forest owner), the regulator may have reasonably good data of volumes and growth at the aggregate level.
} 
control variables are the tax paths, while the producers' control variables are the production of fossil energy and bioenergy as before.

In the present model the solution to the government's optimization problem is in principle simple: The first-best social optimum is achieved if fossil energy consumption is taxed the rate $\tau_{t}$ given by (16) and bioenergy consumption is taxed at the rate $\tau_{t}+\eta_{t}$, where $\eta_{t}$ is given by the social optimum. With these taxes the market outcome solves the following problem:

$$
\max _{\left\{R_{t}\right\},\left\{H_{t}\right\}} \int_{0}^{\infty}\left[B\left(R_{t}+H_{t}\right)-c\left(S_{t}\right) R_{t}-b\left(H_{t}\right)-\tau_{t} R_{t}-\left(\tau_{t}+\eta_{t}\right) H_{t}\right] e^{-\rho t} d t
$$

subject to (1) and (2).

Notice that in this case $\eta_{t}$ is exogenously given to the market participants, chosen by the regulator to be equal to the equilibrium value from the social optimum.

The determination of $R_{t}$ is given by the same equations as in the social optimum. Moreover, at each $t$ the value of $H_{t}$ that maximizes the square brackets in (42) is given by (11). We know that this time path of $H_{t}$ satisfies the constraint (2), which hence is redundant in the optimization problem above. The social optimum therefore solves the optimization problem above.

Under the assumption that climate damages are linear with respect to the carbon in the atmosphere, the optimal tax on fossil energy $(\tau)$ is constant. The optimal tax on bioenergy $\left(\tau+\eta_{t}\right)$ will generally vary over time. The long-run value of this tax is always positive (see eq. (31)), and may be higher (Figure $2 ; \eta_{*}>0$ ) or lower (Figure $3 ; \eta_{*}<0$ ) than the tax on fossil energy. As explained in the end of section 3 , the time path of the difference between these tax rates may be non-monotonic.

The motivation for setting a tax on the energy consumption instead of targeting carbon emission and mitigation was information and verification problems with regards to measuring forest volumes and growth at the micro level. Unfortunately, the government will meet information problems when taxing energy consumption as well. This analysis relied on the assumption that the government was informed about the market response functions, given implicitly by (10) and (11). This is clearly a very strong assumption, and in real life there is no reason to believe that the government would know the exact function forms of the market response 
functions. One can therefore not expect the implemented policies to fully replicate the social optimum.

The reason why we in principle can achieve the first-best social optimum without directly observing the forest growth at the micro level is that in our model this growth only depends on the bioenergy production. In reality, forest owners may be able to influence net carbon emissions also via other channels, e.g. through type of forest and by the way the forests are managed. A tax only on energy consumption will in this case generally not make the market outcome coincide with the social optimum.

\subsection{A constraint on the tax on fossil energy}

So far, we have assumed that the use of fossil energy is always taxed at the optimal rate $\tau$, given by (16). Various political constraints could imply that the actual tax rate in reality is set below $\tau$, say at $\tau^{0}<\tau$. The social optimization problem given in section 3 would then have to be modified, with the government now choosing $H(t)$ taking the market determination of $R(t)$ with the tax $\tau^{0}$ as a constraint. This dynamic second-best optimization problem is considerably more complicated than the problem given by (7) in section 3 . However, with our assumption that $D^{\prime}$ and hence $\tau$ is constant, the steady-state properties for the optimal policy towards $H(t)$ are unaffected, since $R(t)=0$ in this steady state. As before, the optimal policy will be to tax net emissions from the forests at the rate $\tau$, i.e. to tax the use of bioenergy at the rate $\tau$ and to subsidize forest growth with the same rate (as in eq. (41)).

If as argued in the previous subsection it is impossible to subsidize forest growth, the optimal steady-state tax on the use bioenergy will as before be given by $\tau+\eta_{*}$, which is positive (from (31)). If $\tau^{0}$ is sufficiently small, we therefore must have $\tau+\eta_{*}>\tau^{0}$, implying that the optimal tax on the use of bioenergy is higher than the exogenous tax rate on fossil energy. (There may of course be political constraint also on the tax on bioenergy, so that the actual tax will be below the optimal rate.). For larger values of $\tau^{0}$ we may have $\tau+\eta_{*}<\tau^{0}$ since $\eta_{*}<0$ if $\tau$ is sufficiently large. In this case the optimal tax on the use of bioenergy is lower than the exogenous tax on the use of fossil energy. 
If we instead had assumed that $D^{\prime \prime}>0$ the long-run consequence of taxing fossil energy at a less than optimal rate will be slightly different. The long-run contribution of carbon in the atmosphere from burning fossil energy, i.e. $S_{0}-S_{*}$, will be determined by (24) with $\tau$ replaced by $\tau^{0}$, implying that $S_{0}-S_{*}$ is higher the lower is $\tau^{0}$. With $D^{\prime \prime}>0$ it follows from (18) that the long-run climate cost $\tau$ will be higher the lower is $\tau^{0}$. If subsidizing forest growth is ruled out, the optimal tax on tax on bioenergy will as before be equal to $\tau+\eta_{*}$. However, with $D^{\prime \prime}>0$ this tax will depend on $\tau^{0}$, since $\tau$ is higher the lower is $\tau^{0}$. It follows from (39) that $\tau+\eta_{*}$ will be higher the lower is $\tau^{0}$ if $V_{*}>V^{M S Y}$, while the opposite will be true if $V_{*}<V^{M S Y}$. The former case is perhaps most likely, as the climate cost $\tau$ typically will be high in the long run if $D^{\prime \prime}>0$ and fossil energy is taxed at a low rate, and a high value of $\tau$ will imply that the optimal forest volume is large. In any case, it follows from (32) that the long-run volume of the forests should be higher the less fossil energy is taxed, as lower taxation of fossil energy gives a larger climate cost when $D^{\prime \prime}>0$.

\section{Conclusions}

As mentioned in the Introduction, wood-based bioenergy from standing forests is not unproblematic from a climatic point of view: Increasing the harvest from a forest in order to produce more bioenergy may conflict with the direct benefit of the forest as a sink of carbon. We have shown that the optimal volume of the standing forests is higher the higher is the climate cost. For a sufficiently high climate cost, this implies that bioenergy production from forest harvest should be lower the higher is the climate cost, while the opposite may hold for low levels of the climate cost combined with low cost of producing bioenergy.

Even if long-run bioenergy production is lower the higher is the social cost of carbon, the relationship may be reversed in the short run. The reason for this is that in the short run (while low-cost fossil energy resources are still large), an increased climate cost will give reduced production of fossil energy. This in turn will increase the marginal utility of bioenergy, and this effect may be so strong that it is optimal to increase the production of bioenergy.

The social optimum may in principle be obtained in a market economy with 
the correct use of instruments correction for the carbon externalities. The first-best policy is to tax all energy use (fossil and biological) at the same rate per unit gross carbon emissions, and subsidize forest growth (measured in carbon) at the same rate. If this common tax/subsidy rate is set equal to the climate cost, the social optimum is achieved.

In reality, the government will not have detailed and verifiable information about the forest growth at the micro level. It will therefore not be possible to reach the first-best solution using only a tax on net carbon emission. We showed that in our model it is nevertheless possible to achieve the social optimum by suitable taxes/subsidies on the different energy types. Fossil energy should be taxed at a rate equal to the social cost of carbon, while the tax on bioenergy will generally be different. The latter tax should always be positive, but should be lower than the tax on fossil energy provided the climate cost is sufficiently high.

Finally, we considered the possibility of the tax on fossil energy for political reasons being set lower than the climate cost. In this case the optimal tax on the use of bioenergy may be higher than the exogenous tax on the use of fossil energy, even for high values of the climate cost. 


\section{Appendix}

\section{Properties of the phase diagrams}

Consider first the curve for $\dot{\eta}=0$, i.e. (28). As explained in section 3.2, $\eta$ is not defined for $V=V^{\rho}$, where $V^{\rho}$ is defined by $\rho=f^{\prime}\left(V^{\rho}\right)$. Looking at the derivative of the $\dot{\eta}=0$ curve we find $\frac{\partial}{\partial V}\left(\frac{\tau f^{\prime}(V)}{\rho-f^{\prime}(V)}\right)=\left(\frac{\rho \tau}{\left(\rho-f^{\prime}\right)^{2}}\right) f^{\prime \prime}(V)<0$ since $f^{\prime \prime}(V)<0$; hence the $\dot{\eta}=0$ locus is a decreasing function of $V$. For $V<V^{\rho}$ we have $\eta<0$, since $f^{\prime}(V)>0$ for $V<V^{\rho}$. For $V^{\rho}<V<V_{M S Y}$ we have $\eta>0$, since $0<f^{\prime}(V)<\rho$ for these values of $V$. Finally, for $V>V_{M S Y}$ we have $\eta<0$, as $f^{\prime}(V)<0$ for $V>V_{M S Y}$. The curve giving $\dot{\eta}=0$ is thus discontinuous in $V=V^{\rho}$, as the curve tends to $+\infty$ when approaching $V^{\rho}$ from above and $-\infty$ when approaching from below. Moreover, for $V>V^{\rho}$ this curve is is downward sloping and cuts the horizontal axis at $V_{M S Y}$.

Equation (13) may be rewritten as $\dot{\eta}=\rho \eta-f^{\prime}(V)(\tau+\eta)$. In the region $V<V^{\rho}$ we have $f^{\prime}(V)>\rho>0, \eta<0$ and $(\eta+\tau)<0$ along the $\dot{\eta}=0$ curve. Increasing $V$ marginally, while holding $\eta$ constant then yields: $\frac{\partial \dot{\eta}}{\partial V}=-f^{\prime \prime}(V)(\tau+\eta)<0$. This implies that $\eta$ is declining to the right of the $\dot{\eta}=0$ curve, and increasing to the left, for all volumes less than $V^{\rho}$. For volumes between $V^{\rho}$ and $V_{M S Y}$ we have: $0<f^{\prime}(V)<\rho$ and $\eta<0$ along the $\dot{\eta}=0$ curve. In this area $-f^{\prime \prime}(V)(\tau+\eta)>0$, which means that $\eta$ is increasing to the right of the $\dot{\eta}=0$ locus. The last region we need to examine is $V>V_{M S Y}$, where $f^{\prime}(V)<0, \eta<0$ and consequently $(\tau+\eta)>$ 0 . From this we see that $-f^{\prime \prime}(V)(\tau+\eta)>0$, also in this region.

Next, consider the curve for $\dot{V}=0$. The bioenergy cost function is by assumption monotonically increasing in bioenergy production, that is, $b^{\prime}>0$ for all levels of $H$. The bioenergy production is uniquely determined by the steady state volume, $H=f(V)$. Since $b^{\prime \prime} \geq 0$ and $B^{\prime \prime}<0$, the slope $\frac{\partial}{\partial V}\left(B^{\prime}(f(V))-b^{\prime}(f(V))-\right.$ $\tau)=\left(B^{\prime \prime}-b^{\prime \prime}\right) f^{\prime}(V)$ will always have the opposite sign of $f^{\prime}(V)$, and the minimum value of $\eta$ will coincide with the maximum of $f(V)$ at $V_{M S Y}$.

To find in what regions the volume grows and declines, it is useful to start with the first order condition determining the bioenergy production, $B^{\prime}(H)=b^{\prime}(H)+$ $\eta+\tau$. Rewriting the first order condition gives $H=H(\eta+\tau)$, where $H^{\prime}<0$ due to $B^{\prime \prime}<0$ and $b^{\prime \prime}>0$. Using this equation in the growth equation for the volume 
yields $\dot{V}=f(V)-H(\eta+\tau)$. Starting from the $\dot{V}=0$ curve and increasing $\eta$ marginally will lead to a decrease in the bioenergy production and thus an increase in the growth rate of the crops. Thus $V$ is increasing above the $\dot{V}=0$ locus, and decreasing below.

\section{Steady-state effects of increasing the climate cost}

Differentiating (25) and (27) with respect to $\tau$ (after inserting $R_{*}=0$ and $H_{*}=$ $\left.f\left(V_{*}\right)\right)$ gives

$$
\left(\begin{array}{cc}
\left(B^{\prime \prime}-b^{\prime \prime}\right) f^{\prime} & -1 \\
-\left(\eta_{*}+\tau\right) f^{\prime \prime} & \left(\rho-f^{\prime}\right)
\end{array}\right)\left(\begin{array}{c}
\frac{d V_{*}}{d \tau} \\
\frac{d \eta_{*}}{d \tau}
\end{array}\right)=\left(\begin{array}{c}
1 \\
f^{\prime}
\end{array}\right)
$$

implying (32) and (38), where

$$
K=\left(B^{\prime \prime}-b^{\prime \prime}\right) f^{\prime}\left(\rho-f^{\prime}\right)-\left(\eta_{*}+\tau\right) f^{\prime \prime}
$$

To find the sign of $K$, consider the steepness of the curves for $\dot{\eta}=0$ and $\dot{V}=0$. These follow from (28) and (29):

$$
\begin{aligned}
& \left(\frac{\partial \eta}{\partial V}\right)_{\dot{\eta}=0}=\frac{\rho \tau}{\left(\rho-f^{\prime}\right)^{2}} f^{\prime \prime} \\
& \left(\frac{\partial \eta}{\partial V}\right)_{\dot{V}=0}=\left(B^{\prime \prime}-b^{\prime \prime}\right) f^{\prime}
\end{aligned}
$$

In a saddlepoint equilibrium the curve for $\dot{V}=0$ must be steeper (including the sign) than the curve for $\dot{\eta}=0$. From the equations above this implies that

$$
\left(B^{\prime \prime}-b^{\prime \prime}\right) f^{\prime}-\frac{\rho \tau}{\left(\rho-f^{\prime}\right)^{2}} f^{\prime \prime}>0
$$

Inserting (44) into the expression (40) for $K$ gives

$$
\begin{aligned}
K & =\left(B^{\prime \prime}-b^{\prime \prime}\right) f^{\prime}\left(\rho-f^{\prime}\right)-\frac{\tau \rho}{\rho-f^{\prime}\left(V_{*}\right)} f^{\prime \prime} \\
& =\left(\rho-f^{\prime}\right)\left[\left(B^{\prime \prime}-b^{\prime \prime}\right) f^{\prime}-\frac{\rho \tau}{\left(\rho-f^{\prime}\right)^{2}} f^{\prime \prime}\right]
\end{aligned}
$$


From (44) we know that the term in square brackets is positive. Moreover, for $\tau>0$ we have $\rho-f^{\prime}\left(V_{*}\right)>0$. Hence, $K>0$.

The steady-state value $S_{*}$ is determined by $c^{\prime}\left(S_{*}\right)=b^{\prime}\left(f\left(\hat{V}_{*}\right)+\eta_{*}\right.$, implying

$$
\frac{d S_{*}}{d \tau}=\frac{1}{c^{\prime \prime}}\left[b^{\prime \prime} f^{\prime} \frac{d V *}{d \tau}+\frac{d \eta_{*}}{d \tau}\right]
$$

Both terms in square brackets are negative for $f^{\prime}<0$, implying that $\frac{d S_{*}}{d \tau}>0$ for this case (recalling that $c^{\prime \prime}>0$ ). For the case of $f^{\prime}\left(V_{*}\right)>0$ (i.e. low-cost bioenergy with a not too high climate cost) we insert (32) and (38) into the expressions above and rearrange. This gives (33), with the sign following from $K>0$ and $B^{\prime \prime} f^{\prime}<0$.

The expression (39) follows directly from (38).

\section{Forest growth depends on atmospheric concentration of carbon}

In equations (1)- (5) we now have $F\left(V_{t}, A_{t}\right)$ instead of $f\left(V_{t}\right)$. The Hamiltonian (8) is replaced by

$$
\begin{aligned}
\mathcal{H}_{t}= & B\left(E_{t}\right)-c\left(S_{t}\right) R_{t}-b\left(H_{t}\right)-D\left(A_{t}\right)+\kappa_{t}\left[-R_{t}\right]+ \\
& \eta_{t}\left[F\left(V_{t}, A_{t}^{1}+A_{t}^{2}\right)-H_{t}\right]+v_{t}^{1}\left[\frac{3}{4}\left(R_{t}+H_{t}-F\left(V_{t}, A_{t}^{1}+A_{t}^{2}\right)\right)-\alpha A_{t}^{1}\right] \\
& v_{t}^{2}\left[\frac{1}{4}\left(R_{t}+H_{t}-F\left(V_{t}, A_{t}^{1}+A_{t}^{2}\right)\right)\right],
\end{aligned}
$$

The first-order conditions (10) and (11) will be the same as before, but the equations for the time development of the shadow prices are now changed to (using subscripts for partial derivatives of $F$ ):

$$
\begin{aligned}
& \dot{\kappa}_{t}-\rho \kappa_{t}=c^{\prime}\left(S_{t}\right) R_{t} \\
& \dot{\eta_{t}}-\left(\rho-F_{V}\left(V_{t}, A_{t}\right)\right) \eta_{t}=-\tau_{t} F_{V}\left(V_{t}, A_{t}\right) \\
& \dot{v_{t}^{1}}-(\rho+\alpha) v_{t}^{1}=D^{\prime}\left(A_{t}\right)-\eta_{t} F_{A}\left(V_{t}, A_{t}\right)-\tau_{t} F_{A}\left(V_{t}, A_{t}\right) \\
& \dot{v_{t}^{2}}-\rho v_{t}^{2}=D^{\prime}\left(A_{t}\right)-\eta_{t} F_{A}\left(V_{t}, A_{t}\right)-\tau_{t} F_{A}\left(V_{t}, A_{t}\right)
\end{aligned}
$$


Solving for the steady state, we find as before that

$$
\eta_{*}=\frac{F_{V}}{\rho-F_{V}}
$$

From the definition of $\tau$ it follows from the equations above that

$$
\tau=\left[\frac{3}{4} \frac{1}{\rho+\alpha}+\frac{1}{4} \frac{1}{\rho}\right]\left(D^{\prime}-\eta_{*} F_{A}-\tau F_{A}\right)
$$

or, more compactly

$$
\tau=h\left(D^{\prime}-\eta_{*} F_{A}-\tau F_{A}\right)
$$

where $h$ equals the term in square brackets in (50). Inserting for $\eta_{*}$ and rearranging gives

$$
\left[1+\frac{h \rho F_{A}}{\rho-F_{V}}\right] \tau=h D^{\prime}
$$

which may be written as

$$
\tau=k\left[\frac{3}{4} \frac{1}{\rho+\alpha}+\frac{1}{4} \frac{1}{\rho}\right] D^{\prime}
$$

where $k=\left[1+\frac{h \rho F_{A}}{\rho-F_{V}}\right]^{-1}<1$ for $F_{A}>0$ since the steady-state value of $F_{V}$ is smaller than $\rho$. 


\section{References}

Andrade de Sá, S., Palmer, C., \& Falco, S. D. (2013). Dynamics of Indirect Land-Use Change: Empirical Evidence from Brazil. Journal of Environmental Economics and Management, 65(3), 377-393.

Archer, D. (2005). Fate of fossil fuel CO2 in geologic time. Journal of Geophysical Research, 110, C09S05.

Bahel, E., Marrouch, W., \& Gaudet, G. (2013). The economics of oil, biofuel and food commodities. Resource and Energy Economics, 35(4), 599-617.

Berndes, G., Neil, B., Research, J., \& CowieBerndes, A. (2010). Bioenergy, Land Use Change, and Climate Change mitigation (Tech. Rep. No. 03). IEA.

Chakravorty, U., Magne, B., \& Moreaux, M. (2008). A dynamic model of food and clean energy. Journal of Economic Dynamics and Control, 32, 1181-1203.

Crutzen, P. J., Mosier, A. R., Smith, K. A., \& Winiwarter, W. (2008). N2O release from agro-biofuel production negates global warming reduction by replacing fossil fuels. Atmospheric Chemistry and Physics, 8, 389-395.

Farzin, Y., \& Tahvonen, O. (1996). Global Carbon Cycle and the Optimal Time Path of a Carbon Tax. Oxford Economic Papers, 48(4), 515-536.

Grafton, R. Q., Kompas, T., \& Long, N. V. (2012). Substitution between biofuels and fossil fuels: Is there a green paradox? Journal of Environmental Economics and Management, 64(3), 328-341.

Gronwald, M., Long, N. V., \& Roepke, L. (2013). Simultaneous Supplies of Dirty and Green Fuels with Capacity Constraint: Is There a Green Paradox? (CESifo Working Paper No. 4360). CESifo Group, Munich.

Hassler, J., \& Sinn, H. W. (2012). The Fossil Episode (CSifo Working Paper No. 4016). CESifo Group, Munich.

Hill, J., Nelson, E., Tilman, D., Polasky, S., \& Tiffany, D. (2006). Environmental, economic, and energetic costs and benefits of biodiesel and ethanol biofuels. Proceedings of the National Academy of Sciences of the United States of America, 103(30), 11206-11210.

Hoel, M. (2010). Is there a green paradox? (CESifo Working Paper No. 3168). CESifo Group, Munich.

Huang, J. G., Bergeron, Y., Denneler, B., \& Berninger, F. (2007). Response of 
Forest Trees to Increased Atmospheric CO2. Critical Reviews in Plant Sciences, 26(5-6), 265-283.

Macedo, I. C., Seabra, J. E. A., \& Silva, J. E. A. R. (2008). Greenhouse gas emissions in the production and use of ethanol from sugarcane in Brazil: The 2005/2006 averages and a prediction for 2020. Biomass and Energy, 32(7), $582-595$.

Perman, R., Ma, Y., Common, M., Maddison, D., \& Mcgilvray, J. (2003). Natural Resources and Environmental Economics. Pearson Education Limited.

Searchinger, T., Heimlich, R., Houghton, R., Dong, F., Elobeid, A., Fabiosa, J., et al. (2008). Use of U.S. Croplands for Biofuels Increases Greenhouse Gases Through Emissions from Land-Use Change. Science, 319(5867), 1238-1240.

Sletten, T. M. (2012). A Framework for Studying the Environmental Impact of Biofuel Policies. CREE working papers(7).

van der Sleen, P. (2015). No growth stimulation of tropical trees by 150 years of $\mathrm{CO} 2$ fertilization but water-use efficiency increased. Nature Geoscience, 8 , 24-28. 